\title{
Figurative thought, colour categorisation and vantage construal in scientific language is $^{\text {s }}$
}

\author{
José Manuel Ureña Gómez-Moreno* \\ Department of Modern Philology, University of Castile-La Mancha, Av. Camilo José Cela s/n, 13001 Ciudad Real, Spain
}

\section{A R T I C L E I N F O}

\section{Article history:}

Received 25 March 2013

Received in revised form 29 September 2013

Accepted 1 October 2013

\section{Keywords:}

Colour

Vantage point

Metaphor/metonymy

Marine biology

English/Spanish

\begin{abstract}
A B S T R A C T
Research following Vantage Theory (VT) (MacLaury, 1992, 1995, 1997, 2002, 2003) has traditionally focused on general, and occasionally, domain-specific language (e.g. Anishchanka, 2010; Steinvall, 2002, 2011) for modelling colour categorisation, but not on specialised terminology in itself. This research analyses colour categories in the terminology of marine biology in English and Spanish. For this purpose, the study draws on principles from VT and (socio-)cognitive linguistics, including some general premises from cognitive psychology (e.g. Langacker, 1987; Kristiansen, 2008; Plümacher, 2007). Based on a corpus of academic articles and books, this work explores the semantic and cognitive basis of colour, and explains how vantage construal has a bearing on colour dimensions, such as hue, hue distribution, and brightness, when conceptualising and designating sea organisms and processes. The analysis of the terms revealed that figurative thought plays a pivotal role in the formation of specialised concepts through colour attribution both in English and Spanish. The influence of figurative thought is also shown to give rise to inter- and intralingual terminological variation.
\end{abstract}

(c) 2013 Elsevier Ltd. All rights reserved.

\section{Introduction}

There is a large body of research that studies colour naming and categorisation to access and characterise human cognitive processes. In cognitive anthropology, Kay and colleagues (e.g. Berlin and Kay, 1969; Kay et al., 1991) pioneered modern colour term semantics, arguing against the relativism of post-Saussurean linguistics and for a pattern of universality grounded in basic colour terms. Vantage Theory (VT) (MacLaury, 1992, 1995, 1997, 2002, 2003) is currently one of the reference models. Although basically consistent with their foundational tenets, VT refines Berlin and Kay's approach to colour naming and mapping at the lexeme level.

For this reason, a significant number of studies are based on VT today. Particularly interesting are those that follow a usage-based perspective, contextualising the analysis of colour semantics by means of corpus description. For example, Steinvall $(2002,2011)$ analyses colour terms from the Bank of English corpus and from 19th century English travelogues, respectively; Anishchanka (2010) studies colour vantages in painting descriptions. More specifically, these studies shift the focus of analysis from purely denotational or decontextualised meanings of colour terms, which was the predominant trend in early studies (e.g. Brown and Lenneberg, 1954; Berlin and Kay, 1969), to aspects such as the attributive use of

\footnotetext{
This research has been carried out within the framework of the projects RECORD (FFI2011-22397) and VARIMED (FFI2011-23120), both funded by the Spanish Ministry for Science and Innovation.

* Tel.: +34 650637052 .

E-mail address: josemanuel.urena@uclm.es
} 
colours, relations of colour terms to other lexemes and the general status of one colour term in the context of the set of colour terms in a given language.

Current research also highlights and explores meaning extensions of colour as a common phenomenon, which had also been neglected in the past (Steinvall, 2002, p. 189). There are methodologically and theoretically well-grounded studies that discuss the combination of metaphor and colour from cognitivist (Ohtsuki, 2000; Galloway, 2007) and linguistic (Rakhilina, 2007; Niemeier, 2007; Philip, 2011) points of view. Conceptual colour metaphor/metonymy theory (Sandford, 2011) is the most recent model, which builds upon cognitive linguistic constructs, such as vantage points, embodiment, and categorisation to account for the connotation of figurative colour items.

However, to the best of my knowledge, there are no studies on the nature of colour terms in scientific discourse to provide insights into the conceptual and psychological rationale of figurative thought associated with colour perception and categorisation in specialised knowledge. Moreover, little attention has been given to the close relation between type modification and figurative use (Steinvall, 2002, p. 193). To fill this gap, this paper examines a set of figurative terms extracted from a corpus of academic journal articles on marine biology in English and Spanish. The study describes the semantic and cognitive underpinnings of complex terms that designate sea organisms by colour associations. For this purpose, premises from VT as well as general (Langacker 1987, 2000; Kristiansen, 2008) and specific (colour-oriented) (e.g. Plümacher, 2007) principles within (socio-)cognitive linguistics are followed.

The analysis follows a usage-based paradigm insofar as the terms under examination were extracted from texts in marine biology, and contextualised in this field of knowledge. As will be shown, this was crucial for the figurative meaning of the terms. By the same token, this study analyses an aspect of colour categories that is dependent on context: characteristic referential range (the different referents of a category across a range of contexts) (Lucy, 1997, p. 322).

Finally, in some cases the paper analyses terms in English and Spanish from a contrastive perspective. The results obtained provide evidence that inter-cultural regularities and differences can be identified by looking into the way colours are conceptualised and categorised in scientific language.

\section{Materials and method}

The data of the study were extracted from a bilingual corpus that was compiled for the purpose of this study from marine biology academic journals and books. The nature of this corpus ensures the analysis of authentic, that is, not artificially constructed examples. The corpus is made up of 4,588,968 tokens $(2,279,105$ in English and $2,309,863$ in Spanish). Apart from the book The 101 Best Saltwater Fishes, which is also part of the corpus, Tables 1 and 2 list the English-language and Spanish-language journals used in this study, respectively. Ciencias Marinas, a bilingual journal that publishes English and Spanish research papers in all areas of marine science, was particularly useful to identify interlinguistic term pairs.

The Journal Citation Reports (JCR) website was found to be useful for the classification and quality evaluation of the journal articles. The JCR is an on-line service which provides a ranking of the most cited journals published by over 3000 publishers worldwide. Journals are ranked according to a citation index defined by the website itself. As for the Spanish-language journals, only three journals appeared on the list. The rest also meet quality standards. The journal Boletín del Instituto Español de Oceanografía is published by the Spanish Ministry of Science and Innovation. The other journals are published either on the SciELO (Scientific Electronic Library Online) or Redalyc (Red de Revistas Científicas de América Latina, el Caribe, España y Portugal) websites. These websites follow strict norms, guidelines, and selection criteria that guarantee the quality of the scientific journal articles that they host. ${ }^{1}$

The articles were converted into plain text .txt for their processing in Wordsmith Tools ${ }^{\circledR}$, a lexical analysis software. The methodology of this study, which was applied in previous research both for qualitative and quantitative purposes (cf. Ureña and Faber, 2011a,b), consists of a set of highly productive strategies for the semi-automatic retrieval of figurative terms in marine biology. For the purpose of retrieving colour terms, two of these strategies were mostly used in this research (see Ureña and Faber, 2011a,b for the rest of strategies):

(i) searching for target domain vocabulary, including frequently occurring marine biology words, such as fish/pez, shark/ tiburón, coral, sea/(de) mar, and turtle/tortuga, as well as common colour words, such as green/verde, red/rojo, white/ blanco, and yellow/amarillo;

(ii) searching for taxonomic designations, ${ }^{2}$ which were extracted from the checklists included in the academic articles consulted and from the co-text of figurative terms already identified.

Concordances revealed plenty of simple and complex terms. Indeed, as many as 74 figurative colour terms were retrieved by means of these techniques. Concordances of target domain words revealed phraseological units, including figurative colour terms, such as olive ridley turtle. Taxonomic designations are extremely productive markers for metaphorical terms both in

\footnotetext{
1 The SciELO website's criteria for journal evaluation and selection can be accessed at http://www.scielo.org/php/level.php?lang=es\&component=44\&item=2.

2 The taxonomic designation of a species is the Latin name in binomial nomenclature used by the scientific community to classify such a species into a specific taxon. The first and the second constituents of the binomial refer to the genus and the specific name, respectively. Both constituents must be written in italics (e.g. Dicentrarchus labrax).
} 
Table 1

English-language journals.

\begin{tabular}{lll}
\hline English-language journal & JCR Citation Index & Number of tokens \\
\hline Archives of Environmental Contamination and Toxicology & 1.93 & 188,692 \\
Hydrobiologia & 1.784 & 297,844 \\
Coral Reefs & 0.127 & 365,173 \\
Parasitology Research & 0.107 & 214,701 \\
Marine Biology & 0.104 & 356,736 \\
Helgoland Marine Research & 0.082 & 172,441 \\
Environmental Biology of Fishes & 0.068 & 373,249 \\
Marine Ecology & 0.063 & 235,477 \\
Ciencias Marinas & 0.041 & 74,792 \\
& & Total: $2,279,105$ \\
\hline
\end{tabular}

Table 2

Spanish-language.

\begin{tabular}{lll}
\hline Spanish-language journal & JCR Citation Index & Number of tokens \\
\hline Ciencias Marinas & 0.041 & 74,792 \\
Revista de Biología Marina y Oceanografía & 0.032 & 450,335 \\
Boletín del Instituto Español de Oceanografía & 0.028 & 609,998 \\
Investigaciones Marinas & - & 449,506 \\
Revista de Biología Tropical & - & 252,069 \\
Boletín de Investigaciones Marinas y Costeras & - & 473,163 \\
& & Total: $2,309,863$ \\
\hline
\end{tabular}

English and Spanish because they co-occur with the common names of sea organisms in the texts. Again, concordances included a large number of literal and figurative terms, many of which were based on comparison in colour, although shape, function/behaviour were very common as well (cf. Ureña and Faber, 2011a,b).

In the English corpus, the type modification of the figurative items mostly took the form of premodifier or constituent of a single-word compound in the syntactic pattern of the terms. As a premodifier, the pattern was Premodifier (Noun) or Premodifiers (Noun or Adjective + Noun) + Head (Noun). Examples of this pattern are the terms strawberry anemone (Noun as Premodifier + Noun as Head), brown cup coral (Adjective + Noun as Premodifiers + Noun as Head), and leopard coral grouper (Noun + Noun as Premodifiers + Noun as Head). Examples of compound terms are picassofish and fireworm. In Spanish, the most common type modification was Head (Noun) + Postmodifier (Noun), as is the case of tiburón limón [lemon shark] and camarón café [coffee shrimp].

\section{Results and discussion}

The corpus data were analysed by applying premises from VT as well as assumptions and claims from (socio)-cognitive linguistics, including general principles from cognitive psychology on colour description. The results show that the study of colour categorisation provides insights into concept formation in scientific language through metaphor.

As Berlin and Kay (1969) suggest, regardless of which terms are used to describe colours, the underlying cognitive representations of all humans are organised into exactly eleven basic categories (black, white, grey, red, yellow, green, blue, pink, purple, orange, and brown). ${ }^{3}$ This study demonstrates that scientists largely make use of basic colours to conceptualise sea organisms through figurative thought.

\subsection{Colour categorisation based on hue}

The three basic dimensions of colour are hue, saturation, and brightness. This section analyses marine biology terms to describe how scientists rely on different hue-based vantages to construe colour categories, which are subsequently used to figuratively conceptualise and designate sea organisms. Section 3.1.1 discusses examples from an intralingual (English) perspective. Section 3.1.2 deals with examples from an interlingual (English-Spanish) perspective.

\footnotetext{
${ }^{3}$ It should be highlighted that the eleven basic colour term ceiling has been questioned and the twelfth term has been proposed for e.g. Russian, where sinij and goluboy correspond to dark blue and light blue, respectively (cf. MacLaury, 1997, p. 35).
} 


\subsubsection{Intralingual perspective}

The strategies for the semi-automatic retrieval of metaphorical terms from the corpus revealed the English terms fireworm (Hermodice carunculata), sunset cup coral (Leptopsammia pruvoti), and fire dartfish (Nemateleotris magnifica). Contexts (1), (2), and (3) show these terms in the following corpus text examples.

(1) Coral predation by the fireworm $H$. carunculata was investigated by presenting settlers (<3-week-old) and adults of two species of Caribbean corals, Montastraea faveolata and Agaricia humilis, to three different size classes of fireworms under laboratory conditions. (Coral Reefs 32(1), 227-231, 2013)

(2) Sexual reproduction of the solitary sunset cup coral $L$. pruvoti (Scleractinia, Dendrophylliidae) in the Mediterranean: Quantitative aspects of the annual reproductive cycle. (Marine Biology 148(5), 923-931, 2006)

(3) While passive toward most other species, the fire dartfish ( $N$. magnifica) will quarrel with members of its own kind. Fire dartfish have also been known to fight with their close relative, the purple firefish. (The 101 Best Saltwater Fishes, 192 pp., 2007)

These are figurative lexical items grounded both in metaphoric and metonymic mappings, in the same way as the rest of terms analysed in this study. This should not be surprising since metonymy is the basis of the figurative use of colour terms ${ }^{4}$ (Steinvall, 2002, p. 194). The three terms metonymically refer to the different colours that make up the composite fiRE category, which experts use to metaphorically conceptualise and designate one type of sea worm, coral, and fish due to colour analogy.

Apart from inflicting a burning stinging reaction when touched, the fireworm receives its name because of its intense red colour (Fig. 1), which is compared (cross-domain mapping, i.e. metaphor) to one of the colours of fire (metonymy in which the whole, FIRE, stands for the part, or rather, for one of its properties/features, which is RED COLOuR). More precisely, we are confronted with a complex metonymic structure in which FIRE (the whole) metonymically stands for one of its properties, COLouR (the part). colour (the whole) in turn metonymically stands for HuEs (the part), more specifically, for the full range of hues and hue shades that characterise fire. Finally, HUEs (the whole) stands for one single hue, INTENSE RED (the part). In this concatenation of metonymies, the linguistic realisation-that is, fire-is at the surface level, whereas INTENSE RED is at the deepest level.

The sunset cup coral receives its name because of the unsaturated, pale orange colour of its fleshy arms (Fig. 2), which are compared both in colour and shape (metaphor) to the sunbeams when the sun is setting. On close examination, we can speak of a complex metonymic structure. On the surface level is the metonymy where the whole, sUNSET, stands for the part, sun. This cognitive mechanism is linguistically realised as sunset in the term sunset cup coral. On a deeper level is the stage at which sun, the whole, stands for sunbeam, the part. At this stage arises the metaphor because it is the colour and form of the shafts of light coming from the sun that maps onto the elongated pale orange arms of the coral. Since the sun is a ball of fire and the sun metonymically stands for its beams, sunBEAm can be considered a constituent of the category FiRE. The roundish shape of this coral is also compared to the shape of the sun and a cup's circumference, which reinforces the whole metaphor-metonymy structure.

The fire dartfish (Figs. 3 and 4) receives its name because the second part of its body virtually displays the full array of colours that characterise the FIRE category, i.e. yellow, light and deep orange, and even the darkened brown colour of embers in a dying fire (see tail tip of the fish). In addition, the thin, elongated shape of this fish is compared (metaphor) to that of a dart. These intra- (metonymic) and cross-domain (metaphoric) cognitive processes can be interpreted in terms of VT.

Vantage Theory was originally developed to account for the dynamics of colour categorisation, especially continuous and gradual change and the relation of the viewer to the categorisation process (MacLaury, 2002, p. 493). The previously described marine biology terms provide evidence of this gradual cognitive change in scientific language. In fact, gradual change can be associated with vantage points, according to which colour categorisation is similar to spatiotemporal orientation. Specifically, people are able to determine their position in colour space by adopting a particular point of view or vantage point by analogy to the manner in which they keep track of their own position in physical space (MacLaury, 2002, p. 494). Accordingly, we visualise each of the shades and nuances of the range that makes up a particular colour category as we shift from one position (fixed coordinate) to other on the scale. The mobile coordinates, similarity or distinctiveness, will determine the attention emphasis and the scope of the shift to the new position. This claim can be used to metonymically characterise the different hues and hue shades of an entity category (in this case, FIRE) in a whole-for-part relationship, and eventually, to designate other entities (in this case, sea organisms) metaphorically. Thus, we speak of a whole-for-part metonymy with a complex structure, as explained above in the discussion on the figurative nature of terms such as fireworm and sunset cup coral.

In VT, colour categories in most cases consist of three coordinates. The first coordinate is usually a focal colour, which is the inherent fixed coordinate. The second and third coordinates are inherently mobile emphases on similarity (S) and difference (D). On a first level of concentration, $S$ determines that certain shades of colour other than the focal colour are members of the category. On a second level of concentration, D stops the range from extending indefinitely, thus limiting the breadth of the colour category (MacLaury, 2002, pp. 495-496). The FiRE category is composite insofar as it encompasses four hues: yellow, orange, brown, and red. This means that in the analysis of the marine biology terms the focus and breadth of the FIRE category will not only depend on shades of colour, but also on these four hues. Such hues are arranged on a continuum scale

\footnotetext{
${ }^{4}$ The interaction of metaphor and metonymy in marine biology terms can be approached from the prismatic model of metonymy (Geeraerts, 2002). See Section 3.3 for an application of this model.
} 


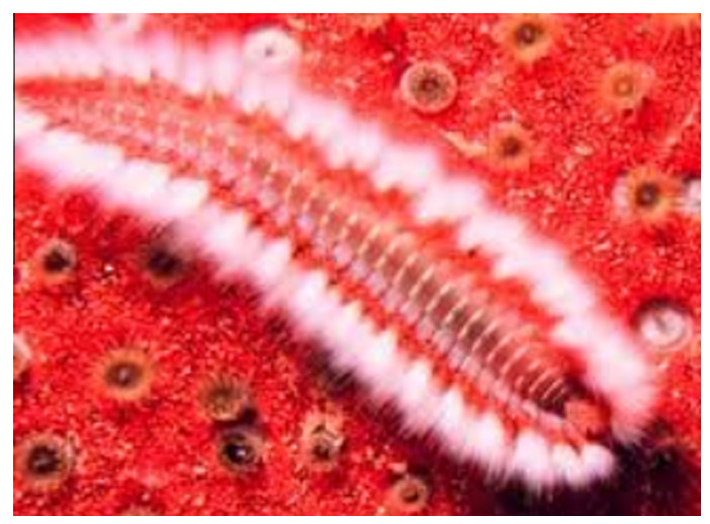

Fig. 1. Fireworm (Hermodice carunculata) on a coral reef.

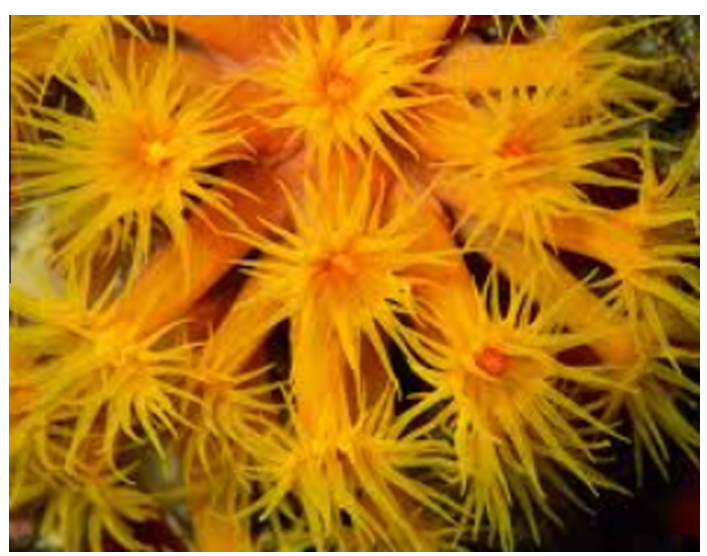

Fig. 2. Sunset cup coral (Leptopsammia pruvoti).

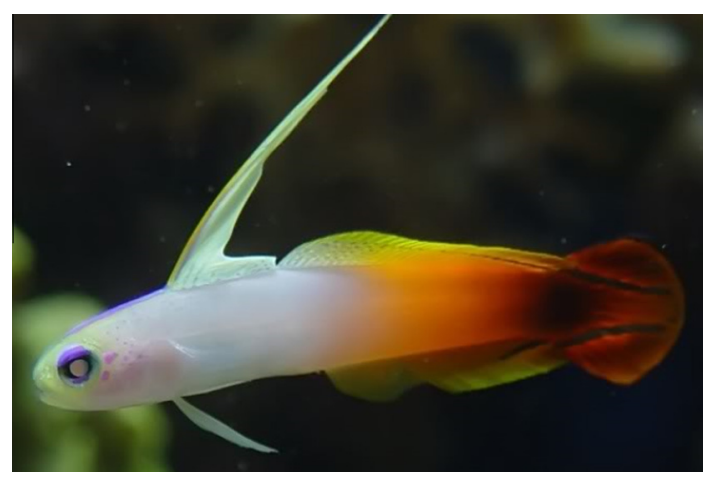

Fig. 3. Fire dartfish (Nemateleotris magnifica).

in the category, with yellow and red as primary colours on the left and right ends, respectively, and orange and brown as secondary hues in the middle. Therefore, it would be justificable to establish the category prototype on an intermediate point, i.e. dark orange.

In comparing the fireworm to fire, scientists on a first level of concentration regard intense red as the fixed coordinate and $\mathrm{S}$, which envisages the rest of hues and shades that flesh out the composite fiRe category, as the mobile coordinate. A second level of concentration can be constructed by zooming in, so that $S$ becomes the fixed coordinate and $\mathrm{D}$, which has been incorporated to the structure, becomes the mobile coordinate. Accordingly, there is emphasis on distinctiveness when the position of yellow is envisioned within the FIRE category since this hue is the furthest to the left from the fixated coordinate, 


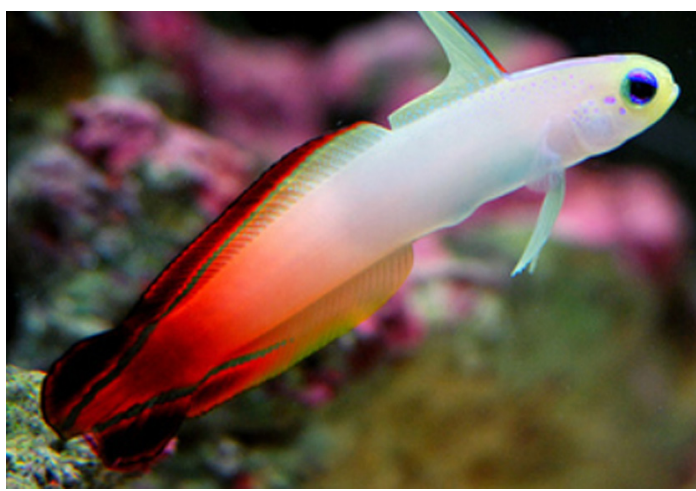

Fig. 4. Fire dartfish (Nemateleotris magnifica).

which is red in this case. Therefore, D delimits the margin of the fIRE category on the left. Scientists are thus adopting a specific vantage point in the category to metaphorically map it onto the concept of $H$. carunculata. This cognitive mapping is then lexicalised as fireworm in marine biology terminology.

In contrast, scientists focus on pale orange to figuratively conceptualise $L$. pruvoti as sunset cup coral. There is thus a vantage change, a shift on the fixed coordinate from intense red to unsaturated orange, which is closer to dark orange, the primary fixed coordinate on the fire-colour scale. In sunset cup coral, the mobile coordinate $\mathrm{S}$ focuses on a specific hue shade of the full array that makes up the FIRE category, as explained below. From a cognitive-linguistic viewpoint, there is a shift in position of the ground (from intense red to pale orange), whereas the figure continues to be $S$ though it compasses a narrower range of shades in the FIRE category) (Langacker, 1987).

VT also describes colour relationships in terms of dominant and recessive patterns, which are sanctioned by emphasis on similarity and distinctiveness, respectively. The term sunset cup coral refers to a pale orange colour, which exhibits a dominant-recessive relationship between the two hues (yellow and orange). This is a relationship of inclusion (MacLaury, 1992, pp. 141-142) since orange has a larger range, retains its size, and continues to cover both foci, whereas the range of yellow is skewed, retracting to the tone surrounding only its focus. For this reason, orange is dominant in the relationship. In addition, emphasis is laid on similarity as the mobile coordinate because orange, as the fixed coordinate, encourages the inclusion of a less representative hue in the category, i.e. standard yellow (see tips of the fleshy arms of the coral in Fig. 2). In contrast to orange, yellow is recessive in sunset cup coral. Accordingly, there is attention to distinctiveness as the mobile coordinate (in fact, standard yellow is identified through $\mathrm{D}$ on a second level of concentration because this colour is on the left margin of the category).

In fireworm, scientists zoom in on one single hue (red) of the FIRE category, coarsely discriminating against the rest of hues. In contrast, fire dartfish does not discriminate hues and shades on the first level of concentration, but it takes all and any hues of the category as a fixed coordinate (from yellow to unsaturated orange to saturated orange and brown to saturated brown to red). As explained below, this is a special case, in which hue shades in the category show markedly unequal membership. On a second level of concentration, attention to distinctiveness-the mobile coordinate-brings yellow and red into the picture because they delimit the breadth of the category on both sides. From a cognitive-linguistic perspective, even though scientists cannot concentrate on the whole range of hue shades of the FIRE category at a time, it is this full array of shades that is mapped onto the specialised concept $N$. magnifica to finally give rise to the metaphor fire dartfish.

It should be noted that a person cannot focus on the whole hierarchical arrangement of a colour category at once. However, the category coordinates comprise a closed system of parameters, in which each part is linked to the others, and thus, implies their existence (MacLaury, 2002, p. 496). Accordingly, a person cannot concentrate on the whole range of hue (shades) of the FiRE category at a time, but the level out of concentration is presupposed.

As mentioned above, the hues in fire dartfish are of markedly unequal membership. Interestingly enough, this leads to another VT phenomenon. Specifically, the term fire dartfish exhibits a relationship of what is known as polarised inclusion under its metonymic nature. Polarised inclusion involves hues that apparently hold a relationship of complementation, whereby their ranges have retracted to separate foci and no one of the ranges encompasses the other's focus. However, they continue to share something. More precisely, in polarised inclusion foci fall outside of each other's respective ranges, but the dominant colour covers most of the recessive colour's range (MacLaury, 1997, p. 527). For this reason, both hues remain polarised. Fig. 5 shows the most common distribution of colours in dart firefish. As can be seen, the hue with the widest range in the FIRE DARTFISH category is orange because its range is larger than-and largely includes-yellow and brown in a relation of dominance and dependence with respect to the latter (MacLaury, 1997, p. 210). The range of orange is larger because it retains its size and covers the rest of hues in the category. This is hardly a coincidence because the hue with the widest range 


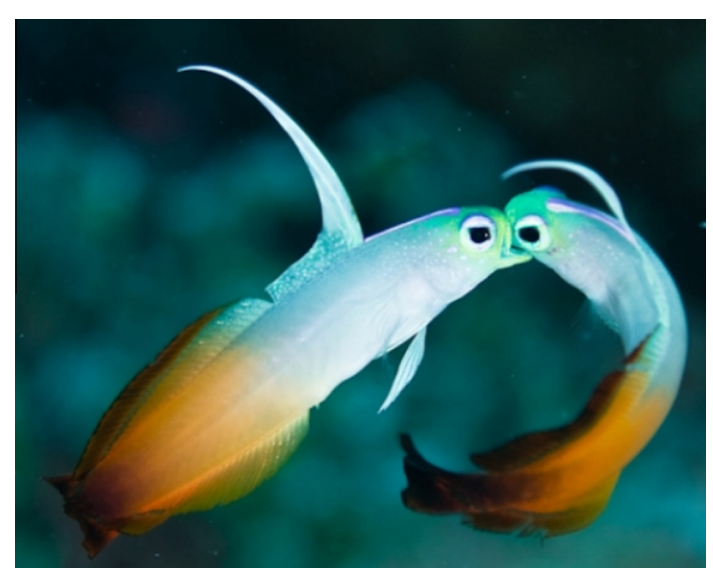

Fig. 5. Commonest colour distribution in dartfish.

in the FIRE category is normally orange too. This shows that inclusion in literal meaning is preserved in figurative meaning to conceptualise and designate a sea organism.

Fire and its warm colours evoke dryness and desiccation since fire is a phenomenon that typically takes place outside water. Surprisingly, this category is used by scientists to designate water organisms. This proves that salient features (in this case, colours) of an element (fire) mostly occurring in a particular environment enable this element to serve as a naming attribute of an entity that is incompatible with such element and its environment. Reasonably enough, metaphor plays a crucial role in this cognitive mapping.

As can be inferred, the function of the colours involved in the conceptualisation of sea organisms is not only to describe these organisms, but also to classify them within a taxonomic nomenclature. As a matter of fact, figurative common names normally designate specific species, as scientific taxonomic designations do. In our analysis, sunset cup coral is used to refer to a coral species and distinguish it from the rest of coral species, such as the brown cup coral. By the same token, the term fire dartfish distinguishes a particular fish species from neighbouring species, such as the zebra dartfish. On many occasions, as is the case here, shape (cup and dart) operates together with colour as motivations for metaphorical transfer in order to rigorously classify sea organisms.

Moreover, the linguistic realisation of the colours in sunset cup coral, and fire dartfish appears, syntactically speaking, in the position of an adjectival attribute modifier in a noun phrase (fire in fireworm used to be a premodifier too, but is now no longer so because of lexicalisation). This is the position that Steinvall (2002, p. 97) highlights for having this classifying function or type modification. Most of the marine biology terms analysed in the next sections also conform to this syntactic pattern. It can thus be concluded that this type modification is intimately linked to some aspects of figurative usage (Steinvall, 2002, p. 97) in specialised language too.

The analysis of these three terms reveals their characteristic referential range (the different referents of a category across a range of contexts) (Lucy, 1997, p. 322). In this sense, fire in fireworm metonymically refers to the referent intense red within the FIRE category, whereas sunset in sunset cup coral refers to the referent pale orange. In contrast, fire in fire dartfish refers to a wider range since it designates the full colour array of the category.

Finally, there are cases in which attention to similarity allows a colour term to be used outside the domain of its normal designation. This is a function typically associated with type modification and meaning extension (Steinvall, 2002, p. 98). Steinvall gives the phrase red hair as an example, and argues that on many occasions red hair is as close to orange or rust as to red, and would possibly be more correctly described as such. This phenomenon also takes place in marine biology. For instance, the term red tide designates an uncontrolled overgrowth of cyanobacteria or dinoflagellates, which causes vivid water discolouring. The colours identified range from red (see the rhombus-shaped accumulation of Noctiluca scintillans, a dynoflagellate, in the middle of Fig. 6), through brown/orange (see Fig. 7), to green.

The term red tide involves two metonymies. In the first, the part, or rather, one property/feature (red colour) stands for the whole (microorganisms). In the second, the part (red microorganisms) stands for the whole array of microorganisms, involving orange, brown, and green colours. In terms of VT, scientists construe a dominant vantage according to which red is established as the fixed coordinate and attention to similarity is strengthened as the mobile coordinate to also include orange, brown, and green in the RED (TIDE) category. Red is dominant with respect to the rest of colours because red is normally the hue with the widest range in the category.

\subsubsection{Interlingual differences}

Although there is no full consensus about their relationship, there is broad agreement that different languages are usually manifestations of different cultures. According to Jameson (2005, p. 5), research on colour categorisation and naming is 


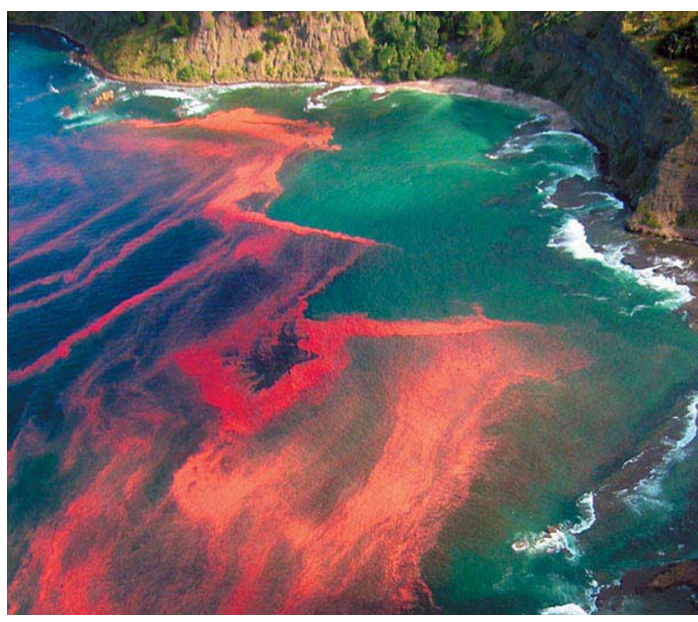

Fig. 6. Red tide of Noctiluca scintillans.

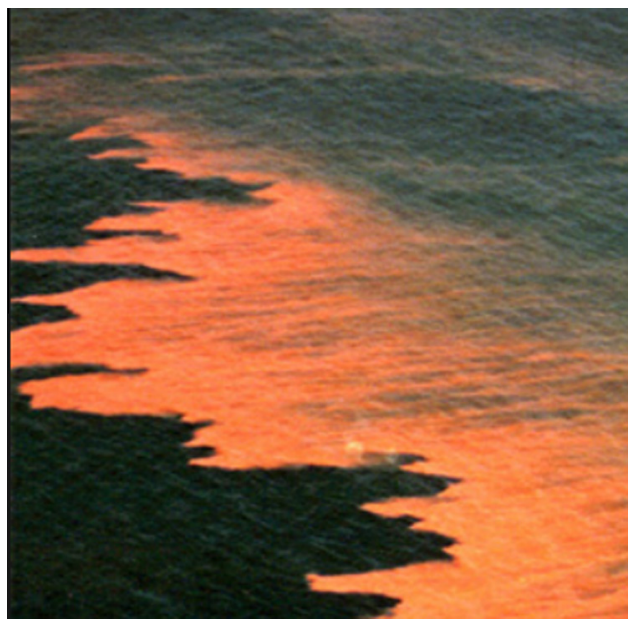

Fig. 7. Red tide of Alexandrium catenella.

particularly important to the study of culture and cross-cultural comparison because it represents one of the few areas of study that is a relevant domain of psychological inquiry across human culture. This inquiry can also be conducted in scientific discourse by contrasting English and Spanish terms in relation to colour categorisation. For example, the corpus data showed the English-Spanish term pair rose shrimp and gamba blanca [white shrimp], which refer to the same organism, as indicated by Parapenaeus longirostris, the taxonomic designation co-occurring with these common names in contexts (4) and (5):

(4) The selectivity of the traditional commercial bottom trawl net employed in Sicily to catch the Mediterranean deepwater rose shrimp, $P$. longirostris, has been assessed. (Hydrobiology 557(1), 113-119, 2006)

(5) A pesar del estado de sobrexplotación o explotación plena de los stocks de merluza europea Merluccius merluccius L., 1758 y gamba blanca $P$. longirostris (Lucas, 1846) detectado por los grupos de trabajo de la FAO, la competencia entre las flotas marroquíes y comunitarias parece ser la razón básica de las restricciones de los acuerdos [...] (Instituto Español de Oceanografía 178, 1-171, 2000)

The term gamba blanca has a literal (non-figurative) meaning. In contrast, rose shrimp has both a metonymic and metaphorical basis. The metonymy is explained as follows. Rose is a non-basic colour term, concretely, what Steinvall (2011, p. 222), inter alia, calls an elaborate colour term. In other words, it is a simplex lexeme that originally designates an object, and secondly, refers to a colour shade by derivation. Specifically, the whole (rose flower) stands for the part (pink colour). The metaphor arises because two different domains of experience, ROSE and SHRIMP, are compared due to colour analogy. As Fig. 8 shows, the hue of the shrimp's exoskeleton looks very much like the hue of a rose. 


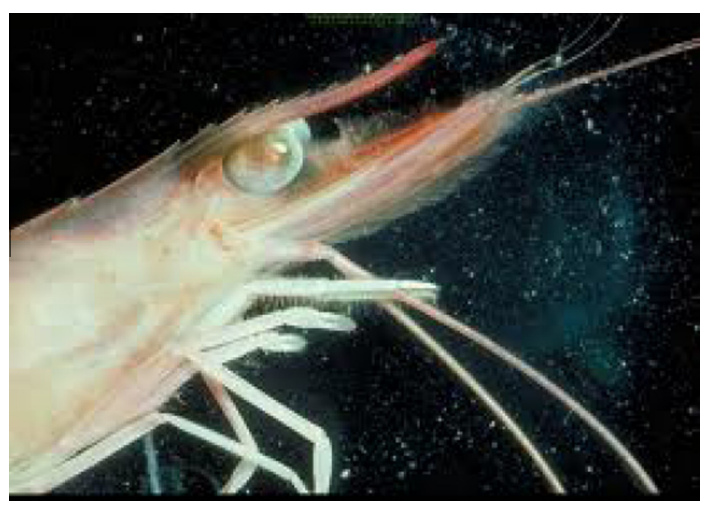

Fig. 8. Shrimp Parapenaeus longirostris.

Red and white are two colour categories sharing a transitional zone where it is not possible to distinguish between both categories. On closer examination, some areas of this shrimp's exoskeleton remain in the undefined zone of the continuous dimension, which can be defined as whitish pink or pinkish white. While English-language scientists opt for whitish pink, their Spanish-language peers are on the other side of the continuum, focusing their attention on the similarity between white and pinkish white. The term gamba blanca indicates that white is the dominant shade in the similarity schema, whereas pinkish white is recessive. In other words, white overrides pinkish white, and obviously, pink. This is an instance of coarse hue discrimination, which does not seem to be in consonance with scientific language. As Langacker (2000, pp. 76-77) notes, zooming in on colour nuances is performed in contexts where subtle colour distinction becomes important. A context of this type is marine biology research, where hues, shades, and brightness are often crucial in distinguishing between two organisms from different taxonomies. Precisely, attention to brightness is discussed in Section 3.2.2.

The analysis of rose shrimp in terms of VT reveals that there is a complementation relation between two colours, which have separate foci. Concretely, this is a stage in complementation at which the ranges of the two categories overlap at their edges, and after a time, a new category intervenes between them. As a consequence, the two original categories are no longer cognitively linked (MacLaury, 1992, p. 142).This phenomenon nicely fits with what occurs in rose shrimp between white and red. Accordingly, two colours with separate foci (red in part of the shrimp's rostrum and white in its walking legs) overlap at their edges (carapace $^{5}$ ), so that the rose/pink category emerges in between and white and red are no longer cognitively linked. It should be noted that the first acception of the colour term rose is dark pink (The American Heritage ${ }^{\circledR}$ Dictionary of the English Language). This means that rose, in its pristine sense, is a hue shade showing a narrower range than whitish pink in rose shrimp, as Fig. 8 shows.

The question now is why English and Spanish conceptualise this shrimp as rose (pink) and white, respectively. This should not be surprising since psychophysical data indicate that there is considerable individual variation in empirically determined perceptual elemental hue settings across observers and to some extent across cultures (Jameson, 2004, p. 91). From a socio-cognitive perspective, the rose shrimp-gamba blanca phenomenon is an example of social categorisation (Kristiansen, 2008, p. 417), which is a cognitive process involving the accentuation of intragroup similarities and accentuation of intergroup differences on relevant continuous dimension.

This inter-lingual difference shows that the universality of experiential basis-in this case, the perception of hues-does not necessarily lead to universally equivalent conceptualisation (Kövecses, 2005, p. 247). It also shows how the collective form of cognition (Sharifian, 2008) critically biases the individual's categorisation schemas, bringing out a significant decrease in his/her cognitive effort (Bernárdez, 2008). In other words, sociocultural patterns underlying the linguistic realisation of concepts guide the individual into perceiving reality in a specific way. As Tajfel (1978, pp. 82-83) explains, stereotypes help us cope with fuzzy differences, which are transmuted into clear ones, and new differences are created where none exist. Accordingly, Spanish-language individuals once transmuted the previously mentioned fuzzy colour zone into separate watertight categories, which then became a stereotype in the conceptualisation of $P$. longirostris in their corresponding scientific circles. In contrast, English-language individuals construed a new colour category out of two separate ones.

The collective form of cognition can also be interpreted from a VT perspective. In fact, VT holds that linguistic variation exists thanks to the plasticity of the categorisation process (vantage construction). As a result, even speakers with a similar background can construct different categories (MacLaury, 2000). This is particularly relevant to the discussion of guelde blanco and ruama in Section 3.2.1.

These examples show that different cognitive vantages of perceptual stimuli are an integral part of the dynamics of cognition in specialised language, according to which "cognition is a dynamic process in which concepts and conceptual structures adapt to the speakers' cultural, social and situational environment” (Fernández-Silva et al., 2011).

\footnotetext{
${ }^{5}$ In crustaceans, the rostrum is the forward extension of the carapace in front of the eyes. The carapace is the dorsal (upper) section of a shrimp's exoskeleton.
} 


\subsection{Different colour dimensions}

This section analyses marine biology terms whose figurative basis draws on colour dimensions other than hue alone. These dimensions are either conventional (shades of colour, brightness, and hue distribution) or non-conventional (illumination).

\subsubsection{Shades of colour: an example of intralingual variation}

The term pairs analysed also demonstrated that differences in conceptualising sea organisms through colour analogy also occur within one language. The difference thus lies in what is known as intra-group (vs. inter-group) diversity (Borofsky, 1994). As exemplified below, this diversity requires established forms of categorising particular shades of colour and designating regular, inter-individual colour effects (Plümacher, 2007, p. 61). In other words, social factors are crucial in colour categorisation, and give rise to intra-group differences both in general and specialised language.

The Canary Islands terms guelde blanco [white guelde] and ruama [no translation into English] are given in contexts (6) and (7). As context (6) explains, guelde blanco is a widespread term on these Islands, whereas context (7) notes that ruama is exclusively used in some areas of the archipielago (see translations between square brackets below)

(6) En Canarias, esta especie (Atherina presbyter), denominada comúnmente guelde blanco, es utilizada como cebo vivo en la pesquería de túnidos desarrollada por la flota artesanal. (Boletín Instituto Español Oceanografía 17(3-4), 239-244, 2001)

[On the Canary Islands, this species (A. presbyter), commonly known as guelde blanco, is used as live bait by smallscale fleets in tuna fishing]

(7) (A. presbyter) Pequeño pez pelágico de color plateado [...] Los pescadores lo suelen utilizar como carnada [...] En algunas zonas de Canarias se conoce con los nombres de "longorón" y "ruama". (Diccionario Básico de Canarismos, 2000, p. 227).

[(A. presbyter) Small pelagic silver coloured fish [...] Fishermen normally use it as bait [...] In some areas of the Canary Islands, (A. presbyter) is known as longorón and ruama]

Guelde blanco and ruama show different vantages in the conceptualisation of two achromatic colours, white and grey. Ruama is a variant of ruana, which means greyish in colour (Diccionario de la Real Academia Española). Guelde is a Canary Islands lectal variant of the general language word gueldo, which designates a fish used by fishermen as bait (Diccionario de la Real Academia Española). The colour of A. presbyter lies in a transition zone of the array of grey shades, specifically, the light grey and greyish white (see Fig. 9). One group of Canary Islanders originally perceived the hue shade of this fish as light grey (ruama), whereas another group perceived the colour as dirty or greyish white (guelde blanco).

In VT terms, the primary or inherent fixed coordinate in the grey category is the purest grey envisionable. In the case discussed here, light grey and white are figuratively lexicalised as ruama and guelde blanco, respectively, to designate a fish. This means that on a first level of concentration light grey and white become the fixed coordinates in ruama and guelde blanco, respectively, exhibiting their corresponding dominant-recessive patterns. In ruama, light grey is dominant because its range is perceptually and cognitively wider than that of white, which is one of the hues that become members of the category thanks to an emphasis on similarity as the mobile coordinate. In contrast, attention to distinctiveness defines white as recessive, involving a narrower range of this hue. On a second level of concentration, D becomes the mobile coordinate, delimiting the margin of the grey category on white. In the case of guelde blanco, white is cognitively-though not perceptually ${ }^{6}-$ dom- $^{-}$ inant over light grey, which is consequently not lexicalised in the term. In other words, the word blanco [white] is proof of the cognitive discrimination of the shades of grey to characterise the fish. Perceptually speaking, however, light shades of grey override white, as shown by Fig. 9.

Context is particularly important for ruama since it is an adjective designating a non-basic colour in everyday language, whereas it is a noun designating a type of fish in marine biology. Since the word can designate both a colour (shade) and a sea organism, the contextual range where ruama can be used is rich.

\subsubsection{Brightness and hue distribution}

There is an on-going discussion both in linguistics and in colour categorisation (see e.g. Biggam, 2007) over which dimension, hue or brightness, is predominant when determining the colour features of an entity. Some scholars (e.g. Allan, 1999, p. 461) argue that neural channels conveying luminance respond faster than those conveying hue sensations. VT is one of the models involved in this discussion. A VT analysis of the conceptualisation of some sea organisms supports Allan's claim. A case in point is the term silverside (Odontesthes bonariensis), which is included in context (8) from the marine biology corpus.

(8) A freshwater fish species, silverside (O. bonariensis) from Mar Chiquita coastal lagoon, Argentina, was analysed for concentrations of several organochlorine pesticides (OCs) and polychlorinated biphenyls (PCBs) in liver [...]

(Archives of Environmental Contamination and Toxicology 38(2), 202-208, 2000)

\footnotetext{
${ }^{6}$ MacLaury (1992, p. 141) refers to perception and cognition as two separate notions. According to him, perception is the receipt by the visual cortex of precortical response to wavelength, whereas cognition is the selective emphasis placed upon those signals after they have been received [my emphasis]. In guelde blanco white is cognitively selected, thus overshadowing grey.
} 


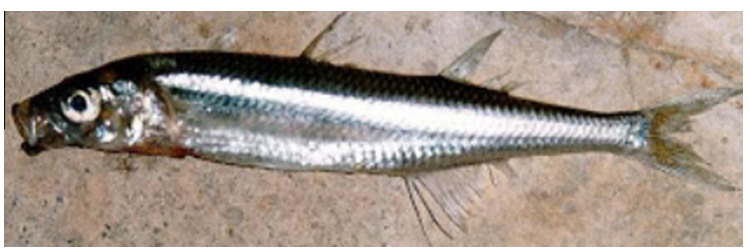

Fig. 9. Guelde blanco or ruama (Atherina presbyter).

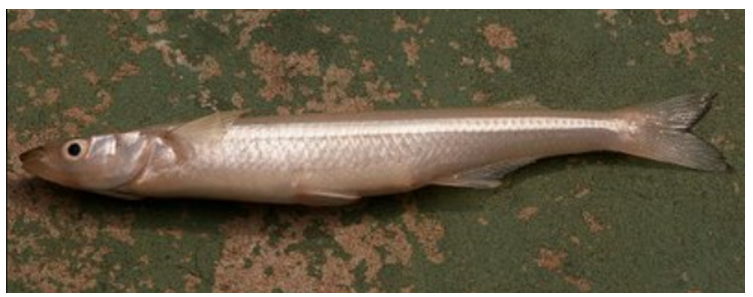

Fig. 10. Silverside (Odontesthes bonariensis).

The term silverside designates a fish that has a dorsal stripe on its skin that longitudinally crosses its whole body (Fig. 10). This fish receives its figurative name because the colour of the stripe (metonymy) is compared (metaphor) to that of silver. Although the stripe is the same hue as the rest of the body (light grey), there is a clear difference in brightness, the colour dimension that becomes the motivation for metaphorical transfer (the natural colour of silver is grey hue + brightness). Proof that both the stripe and the rest of the body have the same hue is that the anterior ventral part of the fish momentarily appears bright in the picture because of the light projection on that area conditioned by our position in space. This anterior part clearly contrasts with the posterior ventral part, which displays no brightness. Most importantly, it is the stripe (silverside) that always remains bright, regardless of light projection and our position. This is what really motivates the metaphor.

In terms of VT, hue is not sufficient as a coordinate to conceptualise and designate the fish 0 . bonariensis based on its colour. Consequently, scientists build their vantages by recruiting a coordinate from the brightness dimension. Accordingly, the difference between the side of the fish and the rest of its body depends on their degree of brightness. In a more detailed explanation, assuming that hue and brightness are working at the same time (silver is grey hue + brightness), dull light grey is established as the fixed coordinate or ground on a first level of concentration. At this level, light grey correlates with zero level of brightness (see the ventral posterior part of the fish in Fig. 10). Sanctioned by attention to similarity as the mobile coordinate, the colour 'light grey at the maximum brightness' enters the structure as figure. On a second level of concentration, this latter colour is fixated as a coordinate (i.e. it becomes the ground) and attention to distinctiveness is emphasised. At this level, 'light grey at the maximum brightness' is distinguished from dull grey hue (see the silver stripe that longitudinally crosses the fish' body in Fig. 10), and delimits the margin of the category (D).

In addition, this is a case of unconscious priming, according to which a stimulus presented first may influence the perception of a second stimulus presented shortly afterwards-even if the first stimulus is not consciously perceived (Fahle, 2007, p. 52). In this sense, even though the dimension of brightness works together with hue to construe a vantage in silverside, the former influences the perception of the latter. In all likelihood, this influence occurs unconsciously because categorisation is an automatic process of which people are largely unaware (Roberson, 2010, p. 169). This claim is also made by VT scholars, such as MacLaury (2002: 494).

The corpus data provided examples showing that colour distribution is also all-important for the metaphorical conceptualisation of sea organisms. Good examples are the terms zebrafish (Danio rerio) and spotted sweetlips (Gaterin flavomaculatus) in contexts (9) and (10).

(9) In this study, the impact of ethynylestradiol (EE2) and 4t-octylphenol (OP) on reproduction in zebrafish (D. rerio) was evaluated using spawning and fertilisation success, gonadosomatic index, and plasma vitellogenin (VTG) levels as endpoints. (Archives of Environmental Contamination and Toxicology 41(4), 458-467, 2001)

(10) At Watamu Park, the SEM, L. miniatus and the spotted sweetlips, G. flavomaculatus, had equal monthly spillover rates. In contrast, the rabbitfish had a lower monthly rate. (Environmental Biology of Fishes 70(4), 363-372, 2004)

The zebrafish receives its name because of the alternative distribution of black and white stripes that transversely cross its body, which look like a zebra's stripes (Fig. 11). It is precisely this colour distribution that causes the fish species $D$. rerio to be metaphorically called zebrafish. In fact, there are other sea organisms that display the same colour combination but different arrangement, and thus, they are not compared to a zebra. An example is the fish in Fig. 12, whose metaphorical-more specifically, synesthetic-common name is spotted sweetlips (Haemulidae family). The cross-sensory metaphor refers to the 


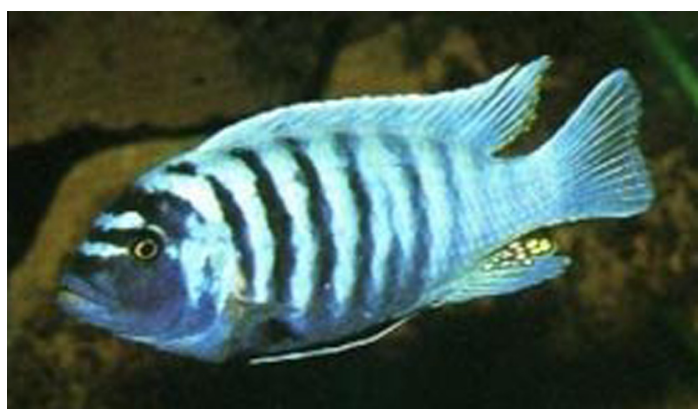

Fig. 11. Zebrafish (Danio rerio).

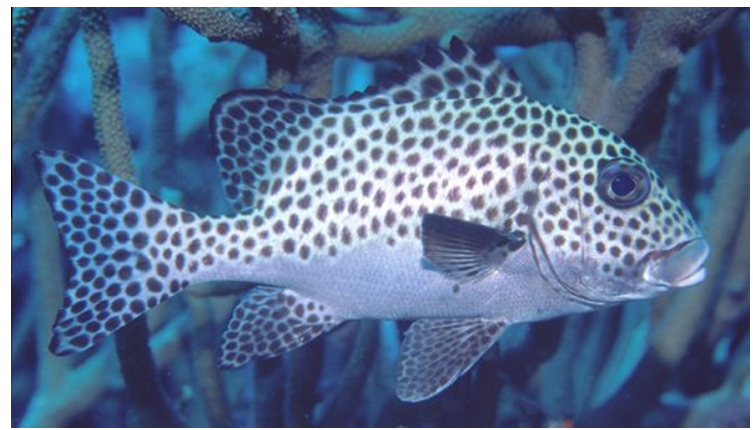

Fig. 12. Spotted sweetlips (Gaterin flavomaculatus).

prominently wide and fleshy upper lip of this fish. The motivation for metaphorical transfer has thus shifted from the colouR domain in zebrafish to the BODY PART domain in spotted sweetlips. The only reference to colour distribution in this fish's name is spotted, which is not metaphorical in nature.

Brightness and hue distribution are conventional colour dimensions. The next section deals with an unconventional dimension as well as with an unconventional combination of colour with another motivation for metaphorical transfer.

\subsubsection{Colour as a changeable property}

Evidence has been provided that the change of colour in light or the change of position of a moving perceiver has an impact on colour conceptualisation. This means that colour is a changeable property, and depends on light and illumination as well as on the colour of the surrounding area (Plümacher, 2007, p. 62).

This psychological effect can sanction the metaphorical grounding of certain colour terms. Let us focus on the figurative term milkfish (Chanos chanos), which is included in context (11). This fish receives its name because of the whitish shade of its skin, which is compared to the colour of milk. This comparison is particularly evident when the animal is seen under water, where the dark colours of the surrounding area (and the sunbeams projecting onto the fish) affect our impression of this fish's colour (Fig. 13). This is the result of an interaction of colours, a phenomenon that has also been recognised by artists for a long time (Plümacher, 2007). In contrast, the skin of the same fish in Fig. 14 does not look particularly whitish.

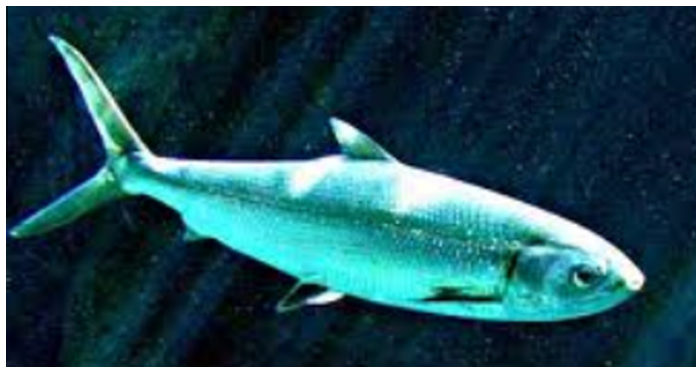

Fig. 13. Milkfish seen under water. 


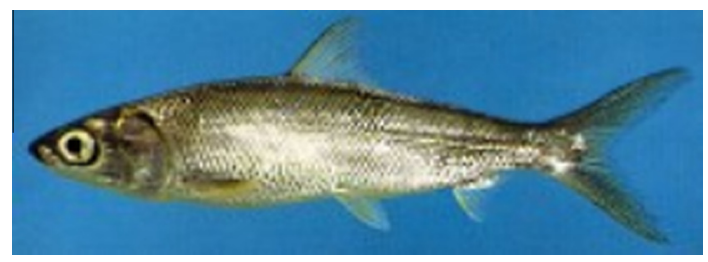

Fig. 14. Milkfish seen outside water.

This is due to the surrounding colour, which is not as dark as that in Fig. 13 because the picture was taken out of water with a lighter background.

(11) Fish kills of milkfish C. chanos and tilapia Oreochromis spp. now occur frequently in brackish, marine, and freshwater farms (ponds, pens, and cages) in the Philippines. (Hydrobiologia 382(1-3), 137-150, 1998).

From the point of view of VT, we can account for colour categorisation in milkfish by considering vantage points from a purely spatial orientation perspective, according to which "people keep track of their own position in physical space" (MacLaury, 1992, p. 141) (my emphasis). In this sense, colour modulation of perceptual input dramatically depends on our physical position and location in space, which leads to viewing the colour of this fish as whiter or darker. In Langacker's terms, the figure (milkfish) is differently characterised depending on the (back)ground (in- or outside water).

\subsection{Colour and texture: an unconventional combination}

There is research showing that there are colour terms whose referents are characterised by additional dimensions of stimuli. Although this is not a common phenomenon, the marine biology corpus revealed that colour and texture can work together to figuratively conceptualise sea organisms. Context (12) contains the English term butterfish (Stromateidae), a food fish that receives this name because of its particularly yellow skin and greasy texture (Fig. 15).

(12) On the basis of the tentacular armature, surface ultrastructure, and morphological measurements of plerocerci obtained from the musculature of butterfishes (Stromateidae), we corroborate an earlier proposal that Otobothrium crenacolle, a commonly reported trypanorhynch cestode from the northwestern Atlantic coast, is a junior synonym of Otobothrium cysticum. (Parasitology Research 86(1), 41-53, 2000)

Again, this is a case of both metaphor (there is a cross-domain mapping from food to FISH) and a whole-for-part metonymy (butter stands for its yellow colour and greasy texture). The interaction of metaphor and metonymy in marine biology terms can be approached from the prismatic model of metonymy (Geeraerts, 2002). This model concerns composite expressions (idioms and compounds), and classifies them according to their motivated and/or isomorphic semantics on the basis of their paradigmatic and syntagmatic relations, respectively. The compound butterfish is a relatively transparent motivated term on the paradigmatic plane for two reasons. Firstly, it can readily be inferred that butter is a whole-for-part metonymy for certain features of this entity. However, it may be more difficult-albeit highly intuitive-to conclude that the most salient features

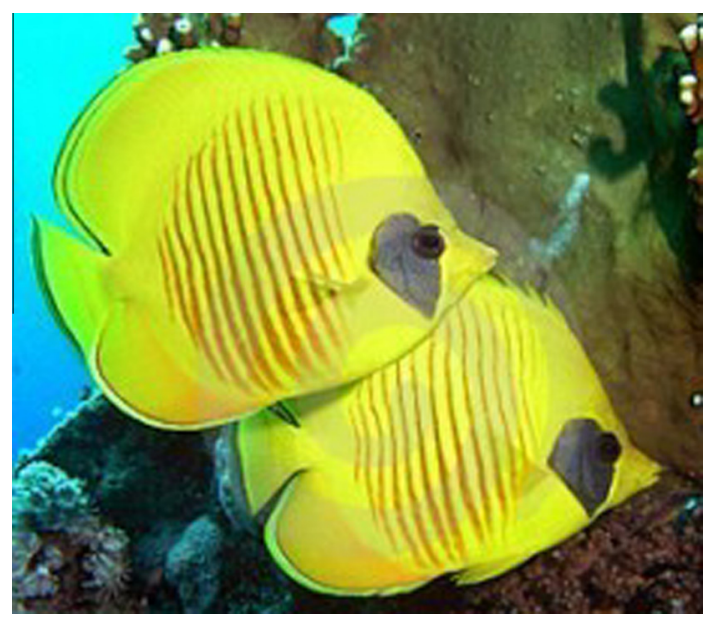

Fig. 15. Butterfish (Stromateidae). 


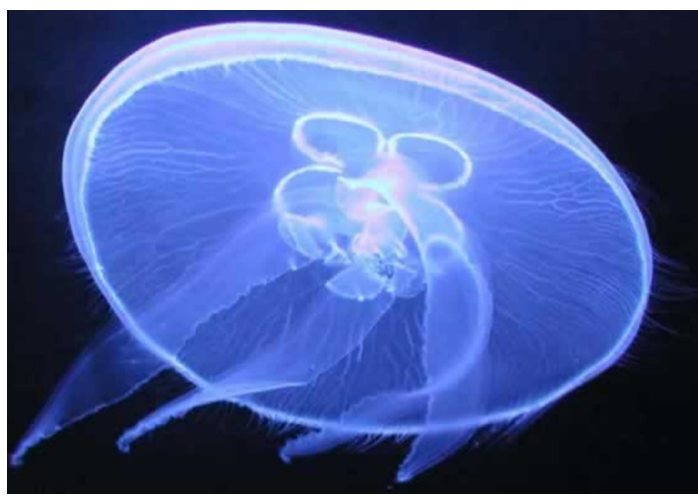

Fig. 16. Moon jelly Aurelia aurita.

of butter, i.e. colour and texture, are involved. Secondly, it is easy to find that BUTTER metaphorically maps onto FISH to characterise this animal physically. This shift from the literal meaning of the individual words (in this case, the shift only affects butter) to their transferred meaning is followed on the syntagmatic plane by their compositional combination into the figurative meaning of the expression as a whole. Accordingly, we can tell that the metonymic meaning of butter isomorphically maps onto its nonmetonymic meaning, and that the literal meaning of fish is preserved (isomorphism) in the figurative expression as a whole.

The most easily perceived feature of the fish participating in the metaphorical mappings is colour, specifically, the yellow hue of butter. According to VT premises, pale yellow is the primary fixed coordinate $(\mathrm{Y})$ of the category since it is the stereotypical hue shade of butter. Based on the term butterfish, intense yellow, which is the common shade of the fish designated by this term, becomes a fixed coordinate in the category. Sanctioned by attention to similarity, pale yellow becomes a member of the category. Therefore, $\mathrm{S}$ is prompting a broader colour category. This process can be explained in terms of dominant-recessive patterns. Scientists need to take a dominant cognitive vantage point at which intense yellow, dominant, overrides pale yellow, recessive. In other words, although there is perceptual difference between both shades, attention to similarity overshadows such perceptual difference.

The additional motivation for metaphorical transfer is greasy texture, which unconventionally works together with saturated yellow to give rise to the term butterfish. Unconventionally is highlighted because the marine biology corpus included very few examples in which the same source entity prompts the metaphor based on two features, colour and texture, as motivations. Butterfish is one of such examples since the single source BuTrer is compared in colour and texture to the target FISH. More common are terms that conjugate both motivation types but stem from different source entities. A good example is moon jelly (Aurelia aurita), a cnidarian (medusa) that is compared to the moon because of its bluish white colour-first source entity-and to jelly because of its soft, semisolid texture-second source entity (see Fig. 16).

From a prismatic perspective, the term moon jelly emerges from a consecutive interaction between metaphor and metonymy since one or more of the motivational links in the semantics of the composite expression involves a sequence of two semantic extensions (Geeraerts, 2002, p. 16). In the first place, there are two whole-for-part metonymies, where the bearer (whole) of a specific feature (part) stands for such feature. Accordingly, JELLY and moon stand for GELATINousness and BLUISH WHITE CoLouR, respectively. In the second place, the concepts jelly and moon are metaphorically extended to the intermediate readings 'texture of medusa like that of jelly' and 'colour of medusa like that of the moon', respectively. This metaphor is at work at the top level of the prismatic structure to designate a type of cnidarian with a moon-like colour. The result is thus a parallel presence of metaphor (top level of the prism) and metonymy (bottom level of the prism) to produce the derived reading of an expression. Consecutive and parallel interactions between metaphor and metonymy are compatible, and thus, can be at work at the same time, as shown by Geeraerts (2002, pp. 16-17) to describe the compound schapenkop [sheephead].

\section{Conclusions}

This paper shows that VT is an effective tool to account for colour categorisation and construal in scientific language, more concretely, in marine biology. Based on corpus data, it is shown that scientists rely heavily on colour to conceptualise and lexicalise sea organisms through figurative thought. Both metaphor and metonymy play a pivotal role in this process. The analysis of the terms explains how experts construe different vantages to designate sea organisms by means of not only conventional (e.g. hue, saturation, and brightness) and unconventional (illumination) colour dimensions, but also by combinations involving colour and an uncommon source for metaphorical extension, such as texture. Colour categorisation through metaphor is also shown to give rise to both inter- and intralingual differences at the cognitive and lexical level. 


\section{References}

Allan, K., 1999. Colors and vantage theory. Language Sciences 21, 449-460.

Anishchanka, A., 2010. Vantage construal in the attributive use of basic color terms: the $\mathrm{A}_{C} \mathrm{~N}$ and $\mathrm{N}$ of $\mathrm{N}_{\mathrm{C}}$ constructions. Language Sciences 32 , $170-183$.

Berlin, B., Kay, P., 1969. Basic Color Terms: Their Universality and Evolution. University of California Press, Berkeley.

Bernárdez, E., 2008. Collective cognition and individual activity: variation, language and culture. In: Geeraerts, R., Dirven, R., Taylor, J. (Eds.), Body, Language, and Mind (vol. II): Sociocultural Situatedness. Mouton de Gruyter, Berlin/New York, pp. 137-166.

Biggam, Carole.P., 2007. The ambiguity of brightness (with special reference to old English) and a new model for color description in semantics. In: MacLaury, R., Paramei, V., Dedrick, D. (Eds.), Anthropology of Color: Interdisciplinary Multilevel Modeling. John Benjamins, Amsterdam/Philadelphia, pp. $171-187$.

Borofsky, R., 1994. On the knowledge of knowing of cultural activities. In: Borofsky, R. (Ed.), Assessing Cultural Anthropology. McGraw-Hill, New York, pp. $331-348$.

Brown, R., Lenneberg, E., 1954. A study in language and cognition. Journal of Abnormal and Social Psychology 49, 454-462.

Fahle, M., 2007. How can language cope with color? Functional aspects of the nervous system. In: Plümacher, M., Holz, P. (Eds.), Speaking of Colors. John Benjamins, Amsterdam/Philadelphia, pp. 35-60.

Fernández-Silva, S., Freixa, J., Cabré, T., 2011. A proposed method for analysing the dynamics of cognition through term variation. Terminology 17 (1), 4973.

Galloway, B., 2007. Metaphors as cognitive models in Halkomelem color adjectives. In: MacLaury, R., Paramei, G., Dedrick, D. (Eds.), Anthropology of Color. John Benjamins, Amsterdam/Philadelphia, pp. 395-404.

Geeraerts, Dirk., 2002. The interaction of metaphor and metonymy in composite expressions. In: Dirven, R., Pörings, R. (Eds.), Metaphor and Metonymy in Comparison and Contrast. Mouton de Gruyter, Berlin/New York, pp. 435-465.

Jameson, K., 2005. Introductory remarks on cognition, culture, and color experience. Cross-Cultural Research 39 (1), 5-9.

Jameson, K., 2004. On the role of culture in color naming. Cross-Cultural Research 39 (1), 88-106.

Kay, P., Berlin, B., Merrifield, W.R., 1991. Biocultural implications of systems of color naming. Journal of Linguistic Anthropology 1, 12-25.

Kövecses, Z., 2005. Metaphor in Culture: Universality and Variation. Cambridge University Press.

Kristiansen, G., 2008. Idealized cultural models: the group as a variable in the development of cognitive schemata. In: Geeraerts, R., Dirven, R., Taylor, J. (Eds.), Body, Language, and Mind (Vol. II): Sociocultural Situatedness. Mouton de Gruyter, Berlin/New York, pp. 409-432.

Langacker, R., 1987. Foundations of Cognitive Grammar, vol. 1. Stanford University Press, Stanford.

Langacker, R., 2000. Grammar and Conceptualization. Mouton de Gruyter, Berlin and New York.

Lucas, H., 1846. Histoire naturelle des animaux articulés. Crustacés, Arachnides, Myriapodes et Hexapodes. In: Aimé, G. (Ed.), Exploration scientifique de l'Algérie pendant les années 1840, 1841, 1842. Imprimerie Nationale, Paris, pp. 1-8.

Lucy, J.A., 1997. The linguistics of “color”. In: Hardin, C.L., Maffi, L. (Eds.), Color Categories in Thought and Language. Cambridge University Press, Cambridge, pp. 320-347.

MacLaury, R., 1992. From brightness to hue: an explanatory model of color-category evolution. Current Anthropology 33 (2), 137-186.

MacLaury, R., 1995. Vantage theory. In: Taylor, J.R., MacLaury, R. (Eds.), Language and the Cognitive Construal of the World. Mouton de Gruyter, Berlin, pp. $231-276$.

MacLaury, R., 1997. Color and Cognition in Mesoamerica: Constructing Categories as Vantages. University of Texas Press, Austin.

MacLaury, R., 2000. Linguistic relativity and the plasticity of categorization. In: Pütz, M., Verspoor, M. (Eds.), Explorations in Linguistic Relativity. John Benjamins, Amsterdam \& Philadelphia, pp. 251-293.

MacLaury, R., 2002. Introducing vantage theory. Language Sciences 24, 493-536.

MacLaury, R., 2003. Vantages on the category of vertical extent: John R. Taylor's “high” and “tall”. Language Sciences 25 (3), $285-288$.

Niemeier, S., 2007. From blue stockings to blue movies: color metonymies in English. In: Plümacher, M., Holz, P. (Eds.), Speaking of Colors and Odors. John Benjamins, Amsterdam/Philadelphia, pp. 141-154.

Ohtsuki, M., 2000. A Cognitive Linguistic Study of Colour Symbolism. Institute for the Research and Education of Language, Tokyo.

Philip, G., 2011. Colouring meaning. Collocation and connotation in figurative language. John Benjamins, Amsterdam.

Plümacher, 2007. Color perception, color description, and metaphor. In: Plümacher, M., Holz, P. (Eds.), Speaking of Colors and Odors. John Benjamins, Amsterdam/Philadelphia, pp. 61-84.

Rakhilina, E.V., 2007. Linguistic construal of colors: the case of Russian. In: MacLaury, R.E., Paramei, G.V., Dedrick, D. (Eds.), Anthropology of Color: Interdisciplinary Multilevel Modeling. John Benjamins, Amsterdam, pp. 363-377.

Roberson, D., 2010. Color in mind, culture, and language. In: Schaller, M., Norenzayan, A., Heine, J., Yamagishi, T., Kameda, T. (Eds.), Evolution, Culture, and the Human Mind. Psychology Press, New York/London, pp. 167-184.

Sandford, J., 2011. Warm, cool, light, dark, or afterimage. Dimensions and connotations of conceptual color metaphor/metonym. In: Biggam, C., Hough, C., Kay, C., Simmons, D. (Eds.), New Directions in Color Studies. John Benjamins, Amsterdam, pp. 205-218.

Sharifian, F., 2008. Distributed, emergent cultural cognition, conceptualisation and language. In: Geeraerts, R., Dirven, R., Taylor, J. (Eds.), Body, Language, and Mind, Sociocultural Situatedness, vol. II. Mouton de Gruyter, Berlin/New York, pp. 109-136.

Steinvall, A., 2002. English Color Terms in Context (Ph.D. dissertation), Umeå University, Skrifter från moderna språk 3.

Steinvall, A., 2011. The use of non-basic colour terms in nineteenth-century English travelogues about northern Scandinavia. In: Biggam, C., Hough, C., Kay, C., Simmons, D. (Eds.), New Directions in Color Studies. John Benjamins, Amsterdam, pp. 219-230.

Tajfel, H., 1978. Social categorisation, social identity and social comparison. In: Tajfel, H. (Ed.), Differentiation between Social Groups. Academic Press, London, pp. 61-76.

Ureña, J.M., Faber, P., 2011a. Strategies for the semi-automatic retrieval of metaphorical terms. Metaphor and Symbol 26 (1), $23-52$.

Ureña, J.M., Tercedor, M., 2011b. Situated metaphor in scientific discourse: an English-Spanish contrastive study. Languages in Contrast 11 (2), $216-240$. 